\title{
A Clinical Study of Role of Noninvasive Ventilation in Community Acquired Pneumonia Patients with Acute Respiratory Failure - A Prospective Observational Study from Telangana, India
}

\author{
Pampana Eshwaramma ${ }^{1}$, Gaddam Ramulu Yadav², Vankayala Veena Reddy ${ }^{3}$, Tarigopula Pramod \\ Kumar', Mandapakala Gopala Krishna Murthy ${ }^{5}$, Gurumurthy Phani Bhushan 6 \\ 1, 2, 3, 4, 5, 6 Department of Pulmonary Medicine, Gandhi Medical College \\ / Gandhi Hospital, Secunderabad, Telangana, India.
}

\section{ABSTRACT}

\section{BACKGROUND}

Community-Acquired Pneumonia (CAP) is defined as "an acute infection of the pulmonary parenchyma. The most important complication of CAP is Acute Respiratory Failure (ARF) and some of them may require Invasive Mechanical Ventilation (IMV) to manage hypoxia and hypoventilation along with appropriate antibiotic therapy. A number of studies, however, indicate that IMV is associated with high rates of serious complications and mortality in patients with ARF. For this reason Non-Invasive Ventilation (NIV) has been used for ARF of diverse aetiologies. The most important rationale for using NIV in early stages of respiratory failure is to decrease the workload on respiratory muscles and improve ventilation by applying positive airway pressure. This may help to overcome an episode of severe ARF without the need for MV. In this study we evaluated the efficacy of NIV in patients with ARF and compare the outcome of using NIV in CAP with ARF patients with and without comorbidities.

\section{METHODS}

This prospective observational study was done on 150 CAP patients in acute respiratory failure who received NIV. It was conducted in the Department of Respiratory Medicine in Gandhi Hospital, Secunderabad, for a period of one year and six months. A comparative analysis of the outcome of using NIV in CAP with ARF patients with and without co-morbidities was carried out.

\section{RESULTS}

In the current study 150 CAP patients with ARF who needed NIV, were treated initially with NIV, antibiotic therapy and other supportive measures as per the American Thoracic Society (ATS) guidelines 32. 95 (63.3\%) of 150 patients were continuously treated with NIV. Apart from these, 55 (36.7 \%) patients required MV. In patients with continued NIV, 93 (98\%) recovered, remaining 2 died with sudden cardiac arrest. In patients who were gone for MV, 12 (22\%) survived.

\section{CONCLUSIONS}

Early intervention by NIV in CAP patients suffering from acute respiratory failure secondary to community acquired pneumonia was found to be successful in avoiding mechanical ventilation and its attendant morbidity and mortality ${ }^{31}$. Early intervention with NIV, identifying risk factors for NIV failure, addressing associated co-morbid conditions will go in a long way in effectively managing these patients by significantly minimizing the ICU and hospital stay. Patients with co-morbidities have more chances of NIV failures. Patients with co morbidities on NIV stayed significantly more number of days in the hospital than patients without co-morbidities. The current study suggests that co morbid patients require more monitoring as compared to patients without co morbidities on NIV.

\section{KEY WORDS}

Community-Acquired Pneumonia (CAP), Non-Invasive Ventilation (NIV), Mechanical Ventilation (MV), Acute Respiratory Failure (ARF), Arterial Blood Gas Analysis (ABG), Intensive Care Unit (ICU), Intubation
Corresponding Author:

Dr. Gaddam Ramulu,

H. NO 3-9-83, Road No 16,

Central Bank Colony, Mansoorabad,

LB Nagar, Hyderabad - 500068,

Telangana, India,

E-mail:drramu15@gmail.com

\section{DOI: $10.14260 /$ jemds/2021/349}

How to Cite This Article:

Eshwaramma P, Yadav GR, Reddy VV, et al.. A clinical study of role of noninvasive ventilation in community acquired pneumonia patients with acute respiratory failure- a prospective observational study from Telangana, India. J Evolution Med Dent Sci 2021;10(22):1686-1691, DOI: $10.14260 /$ jemds $/ 2021 / 349$

Submission 24-12-2020,

Peer Review 25-03-2021,

Acceptance 31-03-2021,

Published 31-05-2021.

Copyright (C) 2021 Pampana Eshwaramma et al. This is an open access article distributed under Creative Commons Attribution License [Attribution 4.0 International (CC BY 4.0)] 


\section{BACKGROUND}

\section{Community-Acquired Pneumonia (CAP)}

CAP is defined as "an acute infection of the pulmonary parenchyma that is associated with at least some symptoms of acute infection, accompanied by the presence of an acute infiltrate on a chest radiograph or auscultatory findings consistent with pneumonia, in a patient not hospitalized for more than 14 days before the onset of symptoms". Streptococcus pneumoniae is the most common aetiologic agent of CAP.1,2

CAP is one of the major causes of morbidity and mortality due to respiratory infections. Depending on the causative organisms, the mortality of CAP ranges from $10 \%$ to $15 \%$ for pneumococcal infection to $60 \%$ for P. aeruginosa. It is the most frequent cause of infection - related death. The clinical syndrome of pneumonia may include generalized symptoms like fever or hypothermia, sweats, rigors, or chills along with pulmonary symptoms, such as cough, sputum production, and dyspnea and pleuritic pain. These may be associated with pulmonary lesions on chest radiography. The major adverse prognostic factors for CAP include co morbid conditions (neurologic or neoplastic disease, cirrhosis, congestive heart failure, respiratory compromise, diabetes, hepatic and renal dysfunction, immune deficiency), bacteremia and multi lobar involvement.

Initial assessment of severity, site - of - care decisions (e.g., hospital vs. outpatient, intensive care unit [ICU] vs. general ward) and empirical antibiotic selection are some of the important areas of management for improving CAP outcomes. $3,4,5$

Some of the complications of CAP are acute respiratory failure (ARF), acute lung injury (ALI), sepsis syndrome (MODS), acute circulatory failure, acute left ventricular failure, acute myocarditis, hematogenous spread and acute abdominal distention etc. Among them ARF is the most common and important life-threatening complication. ${ }^{6}$

There is often a large right to left shunt in pneumonia (particularly when more than one lobe is involved. This leads to a marked fall in the $\mathrm{PaO} 2$ even when the patient is on supplemental oxygen titrated at $4-6$ lit / min. ARF can also occur because of development of Acute respiratory distress syndrome (ARDS) following a fulminant lobar pneumonia.

The multiple shadows seen in both lungs in a patient with a large right to left shunt following a lobar consolidation are now invariably thought to be due to ALI (ARDS), but not due to multi - lobar pneumonia as was earlier believed.

\section{ARF is Two Types ${ }^{1,}$}

1. Hypoxemic Respiratory Failure: (Type I RF / Oxygenation Failure): Failure of lungs or heart to provide adequate oxygenation to meet metabolic needs.

Criteria: $\mathrm{PaO} 2<60 \mathrm{mmHg}$ on $\mathrm{FiO} 2>50$ or $\mathrm{PaO} 2<40$ mmHg on any $\mathrm{FiO} 2$ OR SaO2 $<90$

2. Hypercapnic Respiratory Failure (Type II RF / pump failure / ventilatory failure): It is due to the failure of the lungs to eliminate adequate $\mathrm{CO} 2$.

Criteria - Acute increase in PaCO2 more than $50 \mathrm{mmHg}$.
Non Invasive Ventilation (NIV) ${ }^{\mathbf{7}, 8,9,10,11}$

ARF may require invasive mechanical ventilation to maintain oxygenation along with appropriate antibiotic therapy. Invasive MV is associated with high rates of serious complications and mortality. ${ }^{12}$ To avoid invasive mechanical ventilation associated complications, NIV has been used for acute respiratory failure. The most important rationale for using NIV is to overcome an episode of severe ARF without the need for MV.

NIV is defined as the delivery of Positive airway pressure to the lungs using techniques that do not require an endotracheal airway. The theoretical advantages of this approach include avoiding the complications associated with endotracheal intubation, reducing the incidence of ventilator associated pneumonia, improving patient comfort, preserving airway defense mechanisms, and preserving speech and swallowing without hampering effective cough and expectoration. Furthermore, experimental and clinical work has suggested that noninvasive application of positive pressure promotes effective removal of respiratory secretions by increasing collateral airflow to obstructed lung regions. ${ }^{13,14}$ NIV is now considered a standard of care for selected patients with acute respiratory failure.

The three basic methods of applying noninvasive ventilation are negative - pressure ventilation, abdominal displacement ventilation, and positive - pressure ventilation.

NIV ventilators can be basically classified into pressure or volume present, though some models incorporate both modalities in a single machine, Pressure preset ventilation is now the predominant mode used in NIV. NIV ventilators providing bi - level ventilation are the most popular. Choosing an appropriate interface. ${ }^{15,16}$ (oronasal mask, nasal mask, oral mask \& mouth piece, full face mask, nasal pillows and helmet) is essential for successful NIV. The interface has to provide a good seal and needs to be tolerated by the patient at the same time.

Over the past decade, the use of NIV has increased dramatically. Even though it started with its role in managing ARF associated with Exacerbations of COPD $17,18,19$ it is now used to treat both acute and chronic respiratory failure in a variety of clinical settings. ${ }^{14}$ In recent days NIV is also being used in management of CAP patients with ARF. ${ }^{17}$

\section{Benefits of NIV13,14}

1. Unload the respiratory muscles

2. Preserve speech / swallowing / expectoration

3. Improve gas exchange

4. Decrease left ventricular after load

5. Decrease right and left ventricular preload

6. Reduce the invasiveness of patient management

7. Decrease ICU and hospital stay

8. Diminish the risk of nosocomial infections

9. Decrease complications and mortality

\section{Indicators for Success of NIV}

1. Synchronous Breathing with the ventilator

2. Reduction in Respiratory Rate

3. Reduction in $\mathrm{PaCO} 2$ and correction of $\mathrm{PH}$

4. Lower APACHE Score

5. Less Air Leaking and Less Secretions 
6. Good initial response to NPPV at $1-2 \mathrm{hrs}$

7. Better Neurologic Score

8. Better Compliance

\section{Criteria for Terminating NIV and Switching to} Invasive MV 20,21,22

1. Inability to clear secretions

2. Respiratory rate $>35$ breaths / $\mathrm{min}$

3. Life - threatening hypoxemia: $\mathrm{PaO} 2<40 \mathrm{mmHg}$

4. Severe acidosis $(\mathrm{pH}<7.25)$ and hypercapnia $(\mathrm{PaCO} 2>60$ $\mathrm{mmHg}$ )

5. Impaired mental status

6. Cardiovascular complications (hypotension, shock, heart failure

\section{Objectives}

1. To assess the role of NIV in acute respiratory failure secondary to community acquired pneumonia.

2. To compare the outcome of using NIV in CAP patients in ARF with and without co morbidities.

\section{METHODS}

This study was a prospective observational study of 150 adult cases of community acquired pneumonia with acute respiratory failure who required NIV, admitted in the department of pulmonary medicine, Gandhi Hospital, Secunderabad, over a period of 1 year 6 months. Sample size of 150 was selected by using the formula $\mathrm{N}=(4 \times \mathrm{P} \times \mathrm{Q}) / \mathrm{L}^{2}$, where $\mathrm{N}$ - sample size, $\mathrm{P}$ - prevalence, $\mathrm{Q}=100-\mathrm{P}, \mathrm{L}$ - absolute error (5 - $20 \%$ usually). According AG Ghostal study ${ }^{23}$ prevalence is calculated $(\mathrm{P}=40, \mathrm{Q}=60, \mathrm{~L}=8, \mathrm{~N}=150)$. All the study subjects were recruited after obtaining clearance from ethical committee and taking proper consent from them.

\section{Case Definition}

A case of Community Acquired Pneumonia is defined as a patient coming with 2 or more of the symptoms / physical findings, which develops outside the hospital or within $48 \mathrm{hrs}$ of hospitalization. These clinical features include productive cough, purulent sputum, dyspnea or tachypnea (RR 20 or more / minute), fever (more than $38.0^{\circ} \mathrm{C}$ ) with rigors or chills and pleuritic chest pain along with a new or increasing opacity on chest X-Ray.

\section{Inclusion Criteria}

Patients of CAP in ARF requiring NIV as a mode of management above 18 years of age were taken into the study. These patients were categorised into two groups (Group - I: without co morbidities \&Group - II: with co morbidities)

\section{Exclusion Criteria}

Patients with chronic pulmonary disease, old / active Pulmonary Tuberculosis, Chronic renal failure, retroviral disease and cardiovascular diseases except hypertension are excluded from the study.

\section{Investigations}

Serial plain Chest Radiographs, Sputum for AFB, Sputum for Gram staining \& Culture and sensitivity, Complete blood picture, ESR, Renal function test, Liver function test, Arterial Blood Gas Analysis (ABG), ECG, HIV screening, swab for H1N1\& Other investigations are done as per requirement.

\section{Chest Radiography ${ }^{24,25}$}

In all suspected CAP patients, Chest radiographs were obtained as it confirms the presence of infiltrates, assess the extent of the pulmonary infection, detects pleural involvement, pulmonary or hilar adenopathy.It can also gauge the response to antimicrobial therapy. Radiological response to treatment usually lags behind clinical improvement.

\section{Arterial Blood Gas Analysis 26,27}

Arterial Blood Gas analysis is done as a part of investigation in critically ill patients. It allows evaluation of oxygenation, ventilation and acid base balance in ARF patients. $A B G$ analysis remains the gold standard to assess the severity of ARF and the effects of NIV. Blood gases were sampled at baseline, after 1 and $4 \mathrm{~h}$ of NIV and then at regular intervals depending on the patient's response and with every change to the ventilator settings. It is also done finally before weaning the patient from NIV.

\section{Non - Invasive Ventilation (NIV) $28,29,30,31,32$}

NIV has now become an integral tool in the management of both acute and chronic respiratory failure, both in the critical care unit as well in the home setting. NIV has been used as a replacement for invasive ventilation, and its flexibility also allows it to be a valuable complement in patient management. Its use in ARF is well accepted and widespread.

All consecutive patients received timely standard antibiotic therapy according to the ATS guidelines. NIV was started in all patients who had following criteria as per ATS guidelines. ${ }^{33}$

- Moderate to severe acute respiratory failure

- Tachypnea, (RR more than 25 / min)

- Accessory muscle use or abdominal paradox

- $\quad$ Blood gas derangement $\mathrm{pH}<7.35, \mathrm{PaCO} 2>45 \mathrm{~mm} \mathrm{Hg}$

- $\mathrm{PaO} 2$ / FiO2 $<300$ or SPO2 < $92 \%$ with FiO2 0.5

- Should have no contraindications for NIV Initiation and Titration of NIV: Ventilator settings are made of -

- The ventilator set in the pressure support mode (PSV).

- $\quad$ FiO2 titrated to maintain $\mathrm{SpO} 2 \geq 92 \%$.

- Pressure Support (IPAP): 12 - $15 \mathrm{~cm} \mathrm{H2O}$ (to target tidal volume of $6 \mathrm{ml} / \mathrm{kg}$ ).The maximum IPAP should not exceed $20-23 \mathrm{~cm} \mathrm{H} 2 \mathrm{O}$

- $\quad$ PEEP (EPAP): 5 - $15 \mathrm{~cm} \mathrm{H} 20$ as tolerated to achieve SpO2 $\geq 90-92 \% .5 \mathrm{~cm} \mathrm{H} 20$ was used as initial ventilator support.

- Backup rate: 15 breaths / min

- $\quad$ Backup I:E ratio 1:3

- $\quad$ Trigger: maximum sensitivity

After selecting appropriate ventilator settings and a mask with good seal NIV initiated. Patient's head end of the bed was elevated at 45 degrees. A transparent face mask was 
connected with conventional tubing to the ventilator. The face mask could be removed easily if MV was necessary.

Once initiated on NIV, all patients were put on close monitoring of respiratory and hemodynamic variables hourly. Clinical condition was assessed at regular intervals. ABG was done at the beginning and at $1^{\text {st }} \& 4^{\text {th }}$ hour after starting NIV trial. ECG and arterial oxygen saturation (SpO2) were monitored continuously.

Inspiratory airway positive pressure (IPAP) and Positive end expiratory pressure (PEEP) were stepped up incrementally by $2-5 \mathrm{~cm} \mathrm{H} 20$ was undertaken every 10 minutes or until therapeutic response was achieved, clinically in the form of settling tachycardia, improving SpO2, reduction in tachypnea and work of breathing.

Patients who benefitted from NIV during the first 4 hours of treatment, NIV was continued until the acute cause was resolved. NIV was considered successful if ABG was normalized ie $\mathrm{pH}>7.35$, $\mathrm{PaO} 2$ more than $80 \mathrm{mmHg}, \mathrm{PaCO} 2$ less than $45 \mathrm{mmHg}$, normalization of RR \& HR. Weaning from NIV was planned after patient was stabilized clinically and by ABG.

Patients with signs of clinical deterioration in the form of worsening sensorium, increased accessory muscles of breathing, raising $\mathrm{Pco} 2$, and worsening $\mathrm{pH}$ on $\mathrm{ABG}$ were considered as NIV failures and planned for intubation and mechanical ventilation after consent from the family and managed accordingly.

Patients with co-morbid conditions were evaluated thoroughly and managed as per the existing guidelines.

\section{Statistical Analysis}

Statistical Analysis were performed using Statistical Package for Social Sciences (SPSS Version 22) results are shown as mean and SD. Inferential statistics obtained including $P$ value. Probability of $\mathrm{P}<0.05$ was considered statistically significant. Comparison within groups was performed by $t$ test, as appropriate.

\section{RESULTS}

In this study a total of 150 patients suffering with CAP and ARF, who received NIV were recruited, observed and evaluated. Among those recruited, males were 71 (47.3\%), females were 79 (52.7). The mean age of male patients was $49+13.63$, female patients was $48+16.63$. We also noted in the present study that 87 (58\%) patients presented with co morbidities like HTN, DM, Hypothyroidism, and Obesity, whereas 63 (42 $\%)$ patients had no co-morbidities at presentation.

\begin{tabular}{|ccccc|}
\hline Outcome of NIV & $\begin{array}{c}\text { Number of } \\
\text { Patients (N) }\end{array}$ & $\begin{array}{c}\text { Co-Morbidities } \\
\text { Present }\end{array}$ & Not Present & P - Value \\
NIV Succeeded in & 95 & $50(58 \%)$ & $45(72 \%)$ & \\
NIV Failed in & 55 & $37(42)$ & $18(28 \%)$ & 0.07 \\
Total & $\mathbf{1 0 0}$ & $\mathbf{8 7}$ & $\mathbf{6 3}$ & \\
\hline \multicolumn{4}{r}{ Table 1. NIV Success \& Failure Rate among } \\
CAP Patients with \& without Comorbidities \\
\hline
\end{tabular}

In current study all the patients of CAP with ARF recruited received NIV. Study results show that NIV succeeded in 95 $(63.3 \%)$ patients but failed in only $55(36.7 \%)$ patients. Those patients in whom NIV failed, eventually went on to Mechanical
Ventilation (MV) for further management. In this study success with NIV was seen more in patients without co morbidities (72 \%) as compared to patients with co morbidities (58\%). (Table 1 )

The number of days on NIV were significantly lower in patients of CAP with acute respiratory failure without co morbidities $4.6+1.46(\mathrm{P}<0.05)$. (Table 2$)$

\begin{tabular}{|c|c|c|c|c|c|}
\hline Duration of NIV & Comorbidities & $\mathbf{N}$ & Mean & Std. Deviation & P Value \\
\hline \multirow{2}{*}{$\begin{array}{c}\text { Number of Days } \\
\text { on NIV }\end{array}$} & Present & 50 & 5.440 & 2.1868 & \multirow{2}{*}{0.044} \\
\hline & Not present & 45 & 4.667 & 1.4616 & \\
\hline \multicolumn{6}{|c|}{$\begin{array}{l}\text { Table.2. Number of Days on NIV among } \\
\text { CAP Patients with \& without Comorbidities }\end{array}$} \\
\hline
\end{tabular}

Number of days in ICU \& hospital stay were lower in CAP patients with ARF without co morbidities; in those NIV was success (Table 3).

\begin{tabular}{|c|c|c|c|c|c|}
\hline Days in Hospital & Comorbidities & $\mathbf{N}$ & Mean & $\begin{array}{c}\text { Std. } \\
\text { Deviation }\end{array}$ & P Value \\
\hline \multirow{2}{*}{$\begin{array}{c}\text { Number of Days } \\
\text { in ICU }\end{array}$} & Present & 50 & 9.600 & 5.3146 & \multirow{2}{*}{0.65} \\
\hline & Not Present & 45 & 7.822 & 3.9271 & \\
\hline \multirow{2}{*}{ Total Hospital Stay } & Present & 50 & 13.94 & 8.667 & \multirow[b]{2}{*}{0.127} \\
\hline & Not Present & 45 & 11.49 & 6.801 & \\
\hline in $\mathrm{Pa}$ & $\begin{array}{l}\text { nber of Days in } \\
\text { ts of CAP with }\end{array}$ & & Hospit & Stay are & \\
\hline
\end{tabular}

In this study out of 95 patients started on NIV, 93 patients survived and 2 patients did not survive. Out of 55 patients put on invasive mechanical ventilation 12 patients survived and 43 patients did not survive. In this study, patients survived with NIV were slightly less ICU days and hospital stay in comparison to patients survived with MV (Table 4).

\begin{tabular}{|c|c|c|c|c|c|}
\hline Days & Patients & $\mathbf{N}$ & Mean & $\begin{array}{c}\text { Std. } \\
\text { Deviation }\end{array}$ & $\begin{array}{c}\text { P } \\
\text { Value }\end{array}$ \\
\hline \multirow{2}{*}{$\begin{array}{l}\text { Number of Days } \\
\text { in ICU }\end{array}$} & Survived With NIV & 93 & 9.074 & 5.3020 & \multirow{4}{*}{0.924} \\
\hline & $\begin{array}{c}\text { Survived with Invasive } \\
\text { Ventilation }\end{array}$ & 12 & 9.283 & 6.5430 & \\
\hline \multirow[b]{2}{*}{$\begin{array}{l}\text { Total Hospital } \\
\text { Stay }\end{array}$} & Survived With NIV & 93 & 13.08 & 8.262 & \\
\hline & $\begin{array}{c}\text { Survived With Invasive } \\
\text { Ventilation }\end{array}$ & 12 & 12.42 & 9.793 & \\
\hline Table & $\begin{array}{l}\text { 4. Number of Days in } \\
\text { nong Survived CAP P }\end{array}$ & 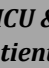 & . & $\begin{array}{l}\text { pital Stay } \\
\& M V\end{array}$ & \\
\hline
\end{tabular}

In current study patients survived with invasive ventilation (NIV failure) had lower oxygen saturation and partial pressure of oxygen at admission and more Respiratory Rate as compared to patients survived with NIV but the difference was statistically not significant. Compared to other studies in the current study NIV success was more (63\%). (Table 5)

\section{DISCUSSION}

Community acquired pneumonia is one of the common respiratory infectious disease complicated with Acute respiratory failure that often requires Ventilatory support with its attendant morbidity and mortality. NIV has been tried successfully in acute respiratory failure due to acute exacerbations of COPD to avoid early endotracheal intubation and Mechanical ventilation. ${ }^{11,14,15}$ Recently published data shows that some studies are done to evaluate the role of NIV in the management of Respiratory failure associated with CAP. A recent review showed a variable success rate ranging from 
$20 \%$ to $76 \%$ for managing respiratory failure by NIV in Community acquired pneumonia.

We noted that in this study 95 (63\%) patients of the total 150 could be managed with only NIV while 55 (36.7\%) patients eventually required endotracheal intubation and mechanical ventilation apart from the routine treatment as per ATS guidelines (Table 1). ${ }^{24,25} \mathrm{NIV}$ was found to be safe and well tolerated compared to MV. Twelve patients survived among the patients who went on to Invasive mechanical ventilation. Success with NIV was comparable to another study done by Andres Carrillo et al. but it is better than the success rate compared with another study done by Michele Carron et al. (Table 5)

\begin{tabular}{|ccccc|}
\hline Sl. No. Characteristics & $\begin{array}{c}\text { Current } \\
\text { Study }\end{array}$ & $\begin{array}{c}\text { Michele Carron } \\
\text { et al. }\end{array}$ & $\begin{array}{c}\text { Andres Carrillo } \\
\text { et al. }\end{array}$ \\
1 & Size & 150 & 64 & 184 \\
2 & NIV Success & $95(63.3 \%)$ & $28(43 \%)$ & $116\{55+61\}(63 \%)$ \\
3 & NIV Failure & $55(36.7)$ & $36(56 \%)$ & $68\{47+21\}(37 \%)$ \\
\hline \multicolumn{4}{|r|}{ Table 5. Comparative Analysis of NIV Success and Failure in Current } \\
& Study with other Studies & \\
\hline
\end{tabular}

This study has revealed a trend towards a higher male to female ratio in patients with Co morbidities receiving NIV, which is similar to the study done by Confalonieri et al. in Italy, as previous studies also suggest that gender is not a negative prognostic factor in outcomes, from Community Acquired Pneumonia.

In this study 87 patients had co-morbidities while 63 patients were without co morbidities. Four different co morbidities were noted among these patients (HTN, DM, Hypothyroidism, and Obesity). Among them hypertension was seen in only 21 patients, diabetes mellitus was seen in 15 patients whereas hypothyroidism was noted in 9 patients. The remaining patients had combination of one or two co morbidities. Present study also showed that patients with co morbidities ( $42 \%$ ) had more chances of NIV failure than patients without co-morbidities (28\%).

It was also noted that the number of days on NIV were more in patients with co-morbidities $(5.4+2.18$ days $)$ when compared with patients without co-morbidities $(4.6+4.16$ days) which was statistically significant $(\mathrm{P}<0.04)$ (Table 2$)$. In overall NIV successful patients ICU days $(P=0.65) \&$ Hospital stay $(\mathrm{P}=0.12)$ was lower in patients without co morbidities as compared to patients with co morbidities. But this difference was not statistically significant (Table 3 ). This was because, patients with co morbidities took more days to recover and required more monitoring than patients without co morbidities. (Table 4)

\section{CONCLUSIONS}

Community acquired pneumonia is one of the most common respiratory infections that leads to acute respiratory failure. These patients have high mortality and morbidity once they land up on endotracheal intubation and mechanical ventilation. Off late non-invasive ventilation has been tried in these patients to avoid MV with variable success. In the present study early intervention by NIV in these patients suffering with acute respiratory failure secondary to community acquired pneumonia was found to be successful in avoiding mechanical ventilation and its attendant morbidity and mortality. Early intervention with NIV, identifying risk factors for NIV failure, addressing associated co-morbid conditions will go a long way in effectively managing these patients by significantly minimizing the ICU and hospital stay. One has to keep an eye constantly on avoiding delayed intubation. Further studies with larger number of cases are needed to strengthen the data and establish the role of NIV in the management of community acquired pneumonia with respiratory failure.

Data sharing statement provided by the authors is available with the full text of this article at jemds.com.

Financial or other competing interests: None.

Disclosure forms provided by the authors are available with the full text of this article at jemds.com.

\section{REFERENCES}

[1] Grippi MA, Elias JA, Fishman J, et al.. Fishman's pulmonary diseases and disorders. $5^{\text {th }}$ edn. McGraw-Hill Education 2015.

[2] Musher DM, Roig JL, Cazares G, et al.. Can an etiologic agent be identified in adults who are hospitalized for community-acquired pneumonia: results of a one year study. J Infect 2013;67(1):11-8.

[3] The etiology, management and outcome of severe community acquired pneumonia on the intensive care unit. British Thoracic Society Research Committee and the Public Health Laboratory Service. Respir Med 1992;86(1):7-13.

[4] Niederman MS, Bass JB Jr, Campbell GD, et al.. Guidelines for the initial management of adults with communityacquired pneumonia: diagnosis, assessment of severity and initial antimicrobial therapy. Am Rev Respir Dis 1993;148(5):1418-26.

[5] Metlay JP, Fine MJ. Testing strategies in the initial management of patients with community-acquired pneumonia. Ann Intern Med 2003;138(2):109-18.

[6] WHO. The top10 cause of death. Updated June 2016. Downloaded on May 2018. http://www.who.int/mediacentre/factsheets/fs310/en/ index.htm.

[7] Confalonieri M, Potena A, Carbone G, et al.. Acute respiratory failure in patients with severe communityacquired pneumonia. A prospective randomized evaluation of noninvasive ventilation. Am J Respir Crit Care Med 1999;160(5 Pt 1):1585-91.

[8] Chastre J, Fagon JY. Ventilator associated pneumonia. Am J Respir Crit Care Med 2002;165(7):867-903.

[9] International consensus conferences in intensive care medicine: noninvasive positive pressure ventilation in acute respiratory failure. Am J Respir Crit Care Med 2001;163(1):283-91.

[10] Nava S, Hill N. Non-invasive ventilation in acute respiratory failure. Lancet 2009;374(9685):250-9.

[11] Mehta S, Hill NS. Noninvasive ventilation. Am J Respir Crit Care Med 2001;163(2):540-77.

[12] Pinhu L, Whitehead T, Evans T, et al.. Ventilator associated lung injury. Lancet 2003;361(9354):332-40.

[13] Andersen JB, Qvist J, Kann T. Recruiting collapsed lung through collateral channels with positive end-expiratory 
pressure. Scand J Respir Dis 1979;60(5):260-6.

[14] Meduri GU. Non-invasive ventilation. In: Marini J, Slutsky A, eds. Physiological basis of ventilatory support: a series on lung biology in health and disease. New York: Marcel Dekker 1998:921-98.

[15] Andersen JB, Olesen KP, Eikard B, et al.. Periodic continuous positive airway pressure, CPAP, by mask in the treatment of atelectasis. Eur J Respir Dis 1980;61(1):20-5.

[16] Guerin C, Girard R, Chemorin C, et al.. Facial mask noninvasive mechanical ventilation reduces the incidence of nosocomial pneumonia. A prospective epidemiological survey from a single ICU. Intensive Care Med 1997;23(10):1024-32.

[17] Bott J, Carroll MP, Conway JH, et al.. Randomized controlled trial of nasal ventilation in acute ventilatory failure due to chronic obstructive airways disease. Lancet 1993;341(8860):1555-7.

[18] Brochard L, Mancebo J, Wysocki M, et al.. Noninvasive ventilation for acute exacerbations of chronic obstructive pulmonary disease. N Engl J Med 1995;333(13):817-22.

[19] Plant PK, Owen JL, Elliott MW. Early use of non-invasive ventilation for acute exacerbations of chronic obstructive pulmonary disease on general respiratory wards: a multicentre randomised controlled trial. Lancet 2000;355(9219):1931-5.

[20] Pierson DJ. Indications for mechanical ventilation in adults with acute respiratory failure. Respir Care 2002;47(3):249-62.

[21] Antonelli M, Conti G, Moro ML, et al.. Predictors of failure of noninvasive positive pressure ventilation in patients with acute hypoxemic respiratory failure: a multicenter study. Intensive Care Med 2001;27(11):1718-28.

[22] Carron M, Freo U, Zorzi M, et al.. Predictors of failure of noninvasive ventilation in patients with severe community-acquired pneumonia. J Crit Care 2010;25(3):540.e9-15.

[23] Ghostal AG. Burden of pneumonia in the community. Journal of the Association of Physicians of India 2016;64(Special Issue):8-11.
[24] Bruns AH, Oosterheert JJ, Prokop M, et al.. Patterns of resolution of chest radiograph abnormalities in adults hospitalized with severe community-acquired pneumonia. Clin Infect Dis 2007;45(8):983-91.

[25] Boersma WG, Daniels JMA, Löwenberg A, et al.. Reliability of radiographic findings and the relation to etiologic agents in community-acquired pneumonia. Respir Med 2006;100(5):926-32.

[26] Raffin TA. Indications for arterial blood gas analysis. Ann Intern Med 1986;105(3):390-8.

[27] Eiting E, Kim HT. Arterial puncture and cannulation. In: Roberts JR, Custalow CB, Thomsen TW, et al., eds. Roberts and Hedges' Clinical procedures in emergency medicine and acute care. 7th edn. Philadelphia, PA: Elsevier 2019:377-93.

[28] Liesching T, Kwok H, Hill NS. Acute applications of noninvasive positive pressure ventilation. Chest 2003;124(2):699-713.

[29] Ferrer $M$, Esquinas A, Leon $M$, et al.. Noninvasive ventilation in severe hypoxemic respiratory failure: a randomized clinical trial. Am J Respir Crit Care Med 2003;168(12):1438-44.

[30] Carrillo A, Gonzalez-Diaz G, Ferrer M, et al.. Non-invasive ventilation in community-acquired pneumonia and severe acute respiratory failure. Intensive Care Med 2012;38(3):458-66.

[31] Kramer N, Meyer TJ, Meharg J, et al.. Randomized, prospective trial of noninvasive positive pressure ventilation in acute respiratory failure. Am J Respir Crit Care Med 1995;151(6):1799-806.

[32] Jolliet P, Abajo B, Pasquina P, et al.. Non-invasive pressure support ventilation in severe community-acquired pneumonia. Intensive Care Med 2001;27(5):812-21.

[33] Metlay JP, Waterer GW, Long AC, et al.. Diagnosis and treatment of adults with community-acquired pneumonia. An official clinical practice guideline of the American Thoracic Society and Infectious Diseases Society of America. Am J Respir Crit Care Med 2019;200(7):e45-67. 